\title{
Using Virtual Reality to Improve Space and Depth Perception
}

\section{Cecilia Sik-Lányi University of Veszprém Veszprém, Hungary}

lanyi@almos.vein.hu

\author{
Zsuzsanna Lányi \\ Ferenc Csolnoky Hospital \\ Veszprém, Hungary
}

lanyi.zs@freemail.hu

\author{
Ádám Tilinger \\ University of Veszprém \\ Veszprém, Hungary
}

tilinger@vnet.hu

\section{Executive Summary}

Space perception is not a congenital faculty of human beings, but it evolves during the first few years of life. Experts are of the opinion that depth perception can be improved during the first 15-16 years of life.

It is very important to help our up coming generation acquire good space perception as this is essential to be able to perform in a high number of occupations.

We have developed virtual reality programs with animations that were used by students to practice space perception tasks and to acquire better space perception.

For testing the programs students were screened for their space perception, and then performed paper tests. One group was permitted to practice using the virtual reality programs; the other used only traditional tutorial methods. A second paper test was then performed. The evaluation of the two tests showed that the possibility of using the virtual reality programs increased the space perception of the students.

Keywords: space perception, depth perception, virtual reality.

\section{Introduction}

Space perception is important not only in many professions but also in everyday life (from becoming a pilot to navigating with a motorcar on a crowded road). Thus it is vital for the up coming generation to acquire good space and depth perception. Most authors are of the opinion that the perception of space can be improved till the age of 15 to 16 years old. On the other hand the Hungarian general education curriculum does not provide much opportunity for the students to develop their depth perception. Therefore, we looked for methods that could be used in schools to practice space and depth perception.

Virtual Reality pictures are not used very much in our schools, but we thought that by presenting tasks on the computer using these techniques, we could develop applications that would help students increase their space perception skills.

In our experiment we have prepared multimedia and virtual reality applications for 10 to 15 year olds to

Material published as part of this journal, either on-line or in print, is copyrighted by the publisher of the Journal of Information Technology Education. Permission to make digital or paper copy of part or all of these works for personal or classroom use is granted without fee provided that the copies are not made or distributed for profit or commercial advantage AND that copies 1) bear this notice in full and 2) give the full citation on the first page. It is permissible to abstract these works so long as credit is given. To copy in all other cases or to republish or to post on a server or to redistribute to lists requires specific permission and payment of a fee. Contact Editor@JITE.org to request redistribution permission. improve their space perception. After evaluating a pilot program, a VRML application has been developed intended for such students. The school children had to take part first in an orthoptic investigation (ophthalmologic screening, visual acuity measurement, space and depth investigation). Then they had to solve traditional paper tests. Virtual reality (VRML) programs, similar to the paper tests, have been developed with animations of the proper solutions of the tasks. Then the test 
Using Virtual Reality to Improve Space and Depth Perception

tasks had to be solved again, and the results were compared with the results of the first test. We looked at the answers on the questions to determine whether the space perception was improved by virtual reality training or not.

Further on we studied what was the relationship between the results of the ophthalmologic space-vision test and the amelioration of space vision by the use of practice.

We have also tested the improvement of space vision using interactive, computer based VRML and Anaglyph programs built to supplement the elementary school mathematics and geometry curriculum and investigated whether the use of solving tasks on the computer has an influence on the students mathematics and drawing accomplishments.

\section{The Use of Virtual Reality in Hungary}

Virtual reality has many applications in education (Johnson, Moher, Ohlsson, \& Leigh, 2001) and in rehabilitation (in the curing of phobias) (Hodges, 2001). In Hungary the use of virtual reality for such tasks is still in its infancy; most often one sees some toys using this technique at exhibitions. At our department we have dealt with multimedia applications for educational purposes for a considerable time. One of our newest projects was the software to compare the efficiency of our multimedia program to improve space vision with the use of a VRML virtual reality application. To our best knowledge no earlier study dealt with the application of multimedia and virtual reality to improve space-vision in Hungary.

\section{The Input Tests}

The original paper test was prepared by Andrea Kárpáti, László Séra and János Gulyás at the Eötvös Loránd University (Kárpáti, Séra \& Gulyás, 2002). It contains 25 test sheets.

Our aim was to give the students tasks that are not boring, keep their attention, are like games, but help to increase space and depth perception; therefore, we have developed computerized versions of these tests. It was important to do this so that the programs can be run on moderately up-to-date computers, as the hardware environment at the schools is usually several years behind the most modern requirements. Due to this some compromise solutions had to be developed.

First we searched for the types of tasks we should create in computerized form. Based on these investigations the tests can be grouped into two capability factors, thus we suppose two partial capabilities. Using Eliot's terms (Eliot, 1987) these are recognition and manipulation. Eliot used these terms to group his tests, but according to our experience these terms describe not only the differences between the tests very clearly but describe also the partial capabilities needed to solve the tests.

\section{Types of Tests}

Producing projections: changing the inner viewpoint, or the production of two-dimensional projections of three-dimensional figures (truncated bodies, shaded slings, wire frame sling figures) by mental rotation and drawing of these. The difficulty of the tasks changes from the concrete to the more abstract analytical tasks. Some of the tasks require an answer, while others are multiple-choice tasks or are of mixed character.

Reconstruction: Based on the projections the test person has to draw the axonometric picture of the body. In performing this task a complex synthetic process is done; a series of inner viewpoint changes are done while the test person compares his/her view with the original and corrects his/her drawing. The picture of the body is mentally reconstructed from the projections in the course of the process even though there is no visible picture. Thus one can say that this picture vibrates at the border of being a two- or three-dimensional picture. It is characterized by being both icon-like and symbolic. 
Seeing the structure: In such tasks one has to match two-dimensional forms that are distorted due to a change in the perspective with pictures where the forms are shown in their proper proportions. The tasks can be subdivided into two groups depending on whether one has to start from the picture showing the form in perspective or in frontal view. This task investigates whether the inner picture of the test person can reflect the real proportions of the body or not. Estimating the perception of the relations and ratios one can guess how accurate the inner mental picture is. This group of tasks permits us to evaluate also the accuracy of the mental corrections of those distortions are that are produced by the distortions due to the viewpoint and the representations. They point to the equilibrium of the perception and cognition, of the visual perception and thinking.

For example, one of the tasks is the recognition of the inner structure of truncated bodies, their representation. One has to imagine how the body can look if viewed from a given perspective. Based on conventional drawings one has to reason what the structural system of the body could be; from the given line structure one has to draw the shaded edges of the body.

Two-dimensional visual space-perception: In these tasks two-dime nsional structures have to be segmented (cut mentally into pieces). In one of the tasks the flat surface has to be cut up so that two congruent parts are produced. In another task the cutting is made in such a form that from the parts rectangles can be assembled. In the first case a well-known plane figure has to be kept in mind, while in the second one the picture has to be newly structured without knowing anything about its construction. The execution of the tasks is influenced by use of the analytical and synthetic mental processes.

Mental transformation of figures: This task needs the tracking of activities consisting of compound tasks with many transformations. Examples of such tasks are the iterative folding of papers according to a picture and the building of a cube based on its mesh-drawing (see Figure 1.) One of these tasks is a compound task containing two sub-tasks. One of them is a "noisy" task: the pattern recognition in case of misleading formations. (The noise is produced by the edges of shapes that are obscured. These baffle the observer.) The other part of the tasks contains mental rotations of the figure to be able to compare it with
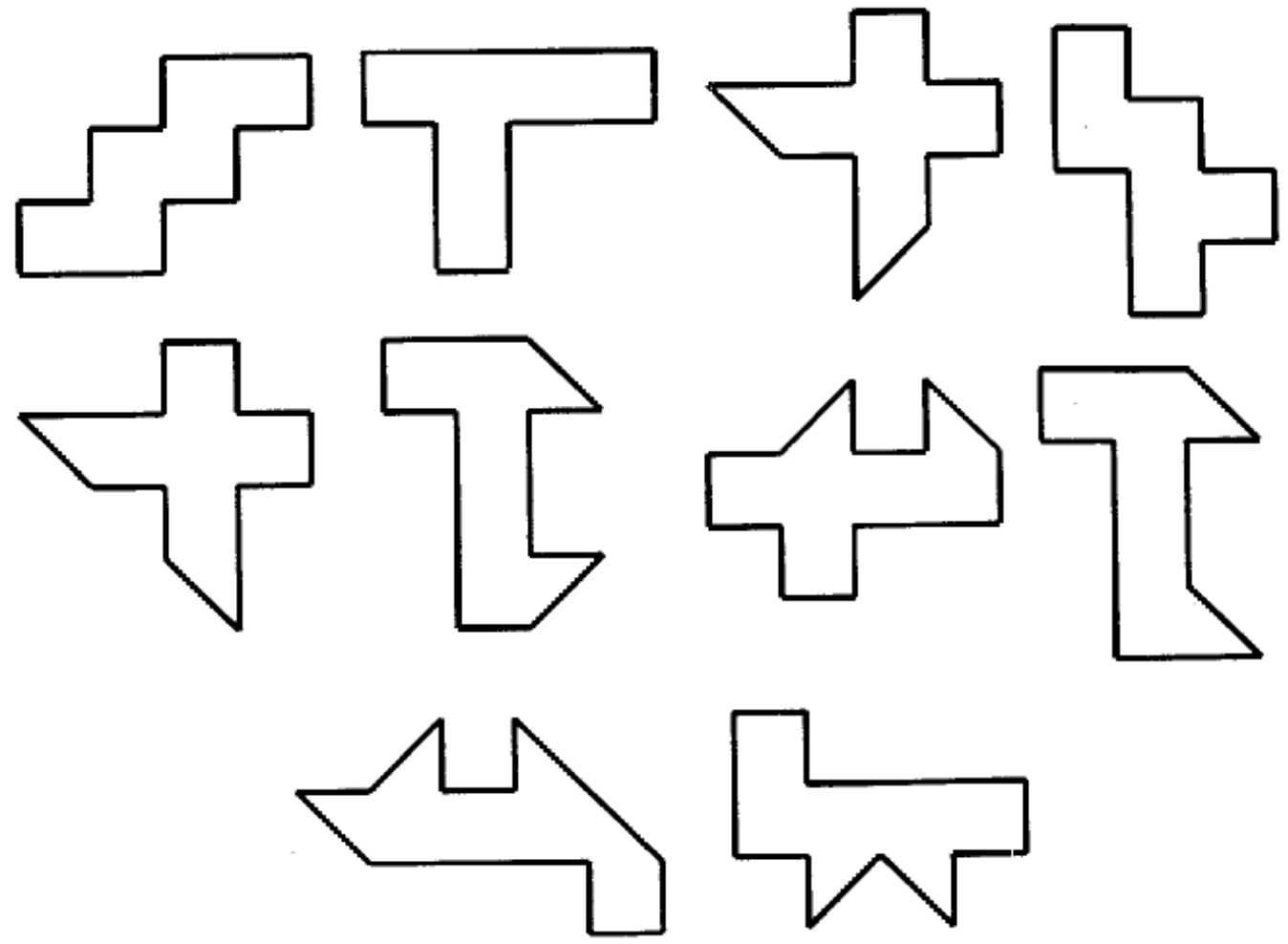

Figure 1: Which one can be the mesh-diagram of a cube? 
the different projections shown. This task, called usually "rotation of the cube," contains the manipulation of the space of the different representations, and quite frequently, also uses other strategies of solution. In the case of a rotated cube one is confronted with an assembly of models shown in different orientations; this needs to mobilize the capability of recognition. Conceptual operations might also play a role in the solution of this task, but this is not required.

The recognition and visualization of three-dimensional bodies: In one of the task-types the position of an object has to be identified in case the visual information is not complete and the body has to be illustrated. A body in space has to be recognized and depicted in a situation that not all-visual information is available. If one recognizes the type of the object the drawing will be possible. Another such task is when the visual information seems to be contradictory; the picture is too crowded (less would be more). (Figures 2 and 3 show some examples.)
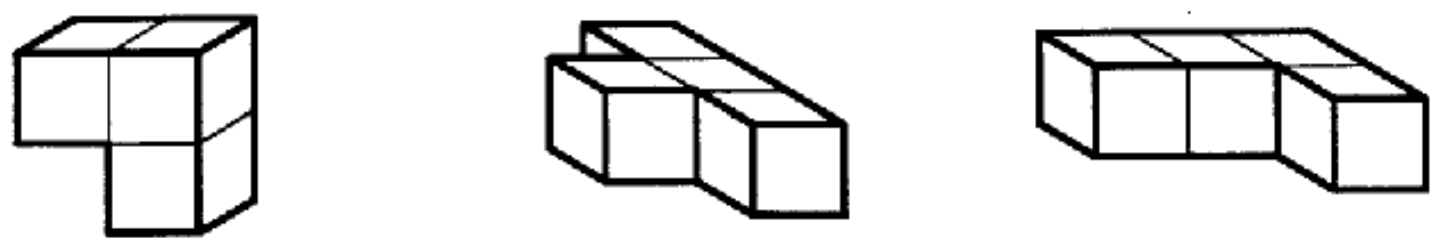

Figure 2: Compile from such identical bodies mesh-configurations as seen in Figure 3.
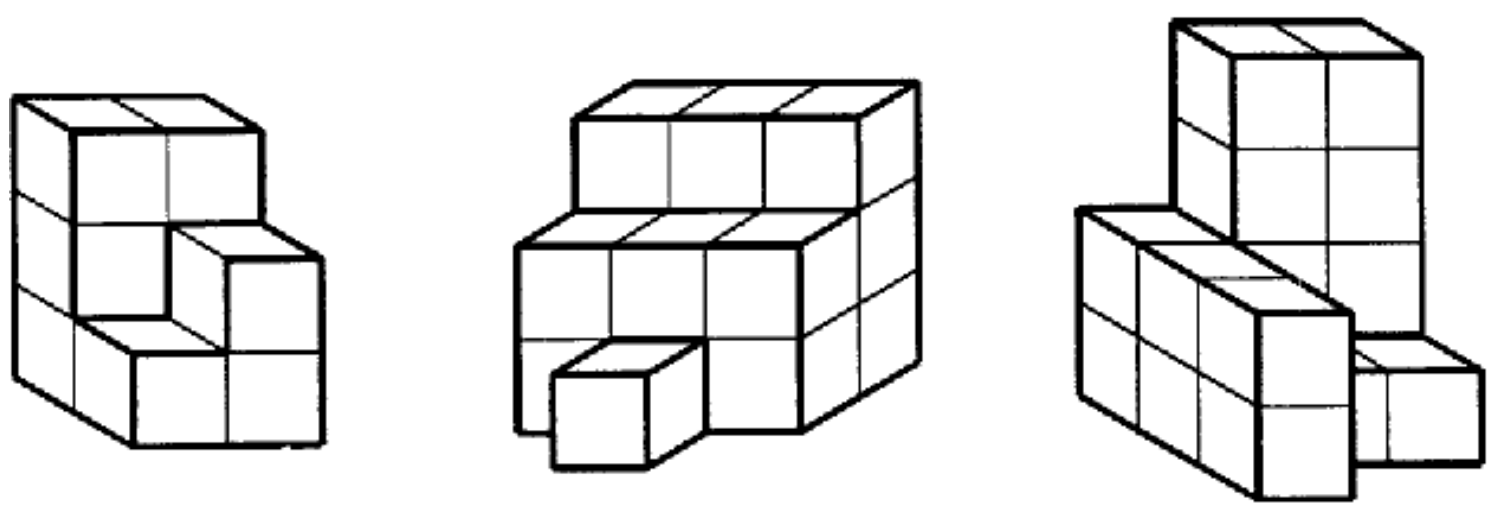

Figure 3: The configurations that have to be put together.

There are tasks in which the coherent parts of a three-dimensional structure have to be recognised and paired. The amendment of bodies has to be done, from "negative" examples of bodies a structure has to be built, and then the mental picture has to be identified using a given set of samples. Using conventional drawings one has to find out the inner structure of the bodies, identify line, and draw edges.

Dynamic vision: This measures the conception of movement. Such a task is the so-called "shoe-lace" task, as seen in Figure 4, where we see a complicated bow. If the ends of the line are drawn a knot might be produced, or not. The task is to visualize what happens when the line is drawn, will a knot be produced or not. Such tasks can be categorised into two sub-classes: in one of them the student has to move the whole picture, and in the other one parts of the picture have to be mentally moved. 

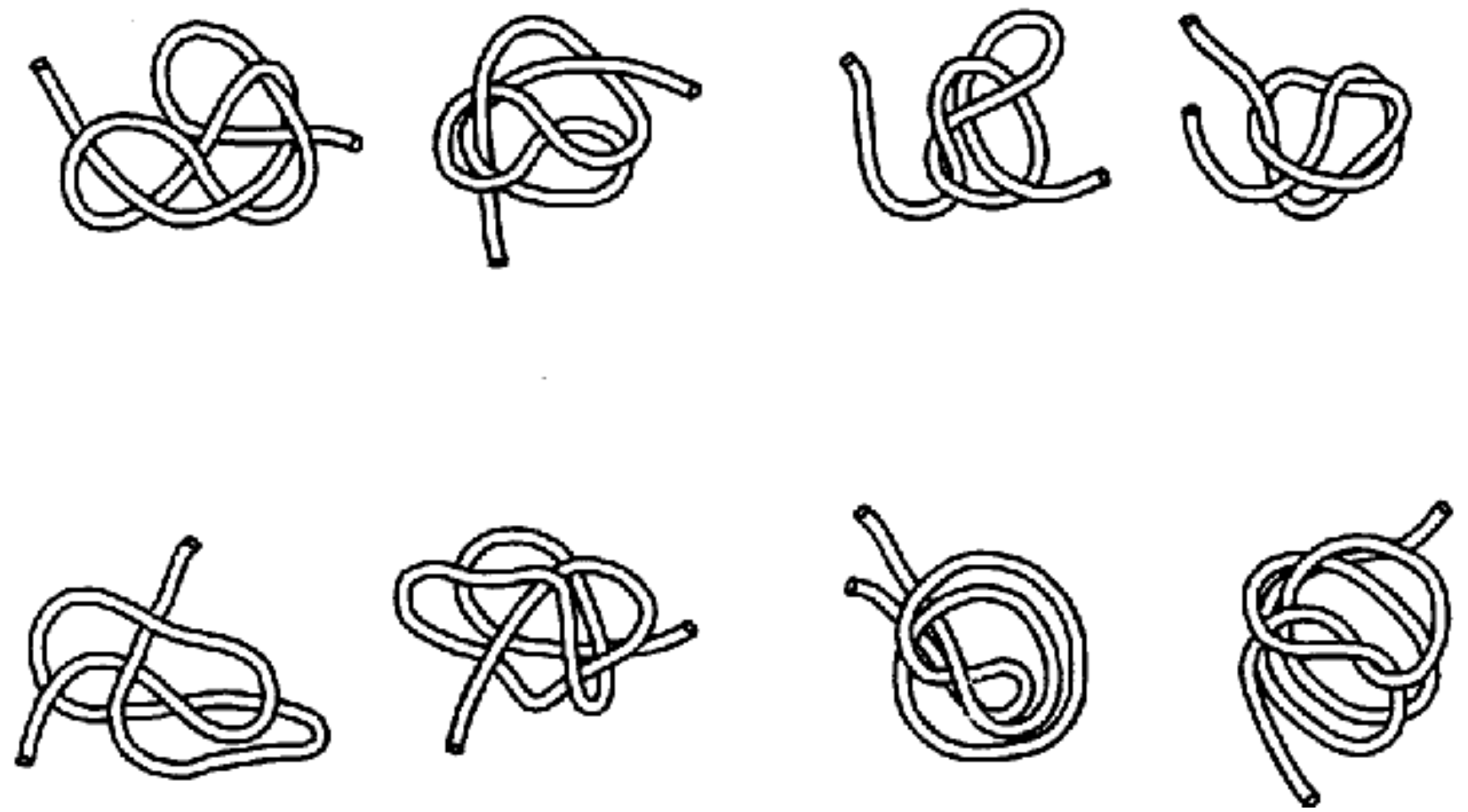

Figure 4: The shoe-lace task.

The tasks can be categorized also in other groups:

Two- and three-dimensional tasks.

- Static and dynamic tasks.

- Tasks where answers have to be given and multiple-choice tasks (within these groups: has the drawing to be completed or has a new drawing to be prepared).

- Problems drafted in an abstract or concrete situation.

- Tasks with one or more solutions (the latter ones can measure also the possibility of creativity).

\section{Description of the Software}

The tests described in this paper were created using two software programs. The main menu was written in HTML, into which VRML applications have been embedded. This has the advantage that no translation is needed to get an executable file; only a VRML browser has to be downloaded. Both programs start with the test tasks according to the main menu points, and show animated solutions.

This choice had the advantage that the programs could be executed even in schools with moderate computer hardware capacities. In our country it is general practice to have Windows operating systems running on the computers, and these have a built in browser (Internet Explorer). To build the threedimensional objects we used the VRML language. This enables interactivity, too, and can be used if a VRML browser (e.g. CosmoPlayer) has been downloaded.

The main menu starts with the selection of the task. The student can go through all the tasks one by one, or can select one to be studied at will.

All the parts enable the active participation of the student. This has been enabled by the possibility of direct manipulation. The student can not only be engaged in the solution of the task, but can also check 
whether he or she found the correct solution or not. The programs do not score the performance of the student, but help to get the correct solution by showing the best examples by the help of animations. The programs are user friendly and easy to use; the student does not have to have computer knowledge. (The programs can be downloaded from our WEB site http://vision.vein.hu/mmvv/ (Lanyi, 2002).)

Figure 5 shows an example of a test we used in evaluating the development of space vision of the 15 year-old students in a high school (see next section: The course of the investigation).

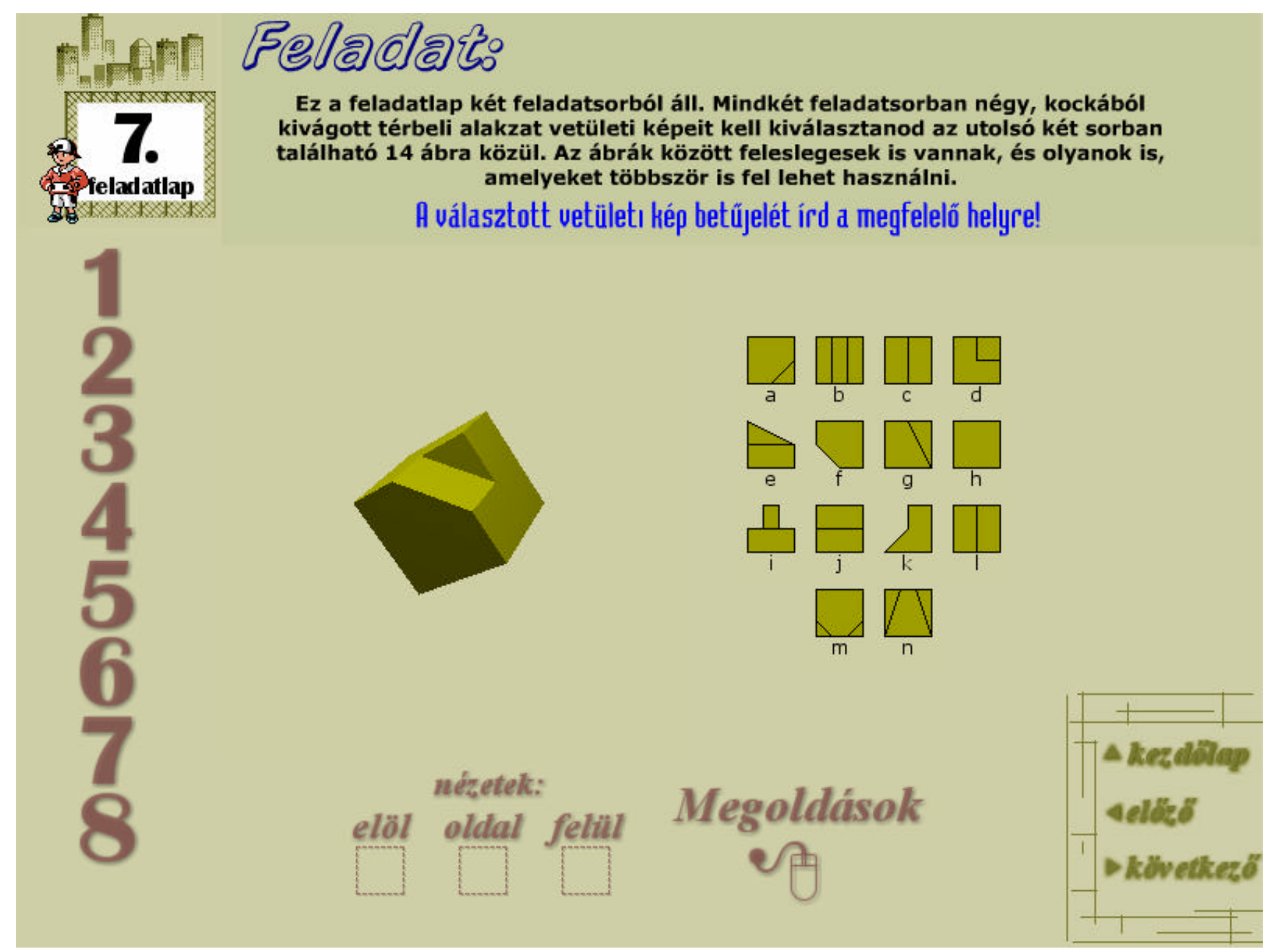

Figure 5: Test sheet No. 7 of the group of tests used in the high school studies: At the top of the screen you see: "7th test sheet; Task: This task consists of two sub-tasks (here the task description is formulated). The student has to input the letters a,b,c, etc. at the bottom in the middle that represent the front (elöl), side (oldal) and top (felül) view of the truncated cube. Clicking on "Megoldások" one can see the proper answer. At the left lower corner possibilities to navigate to the beginning, the previous or next task are made available. 


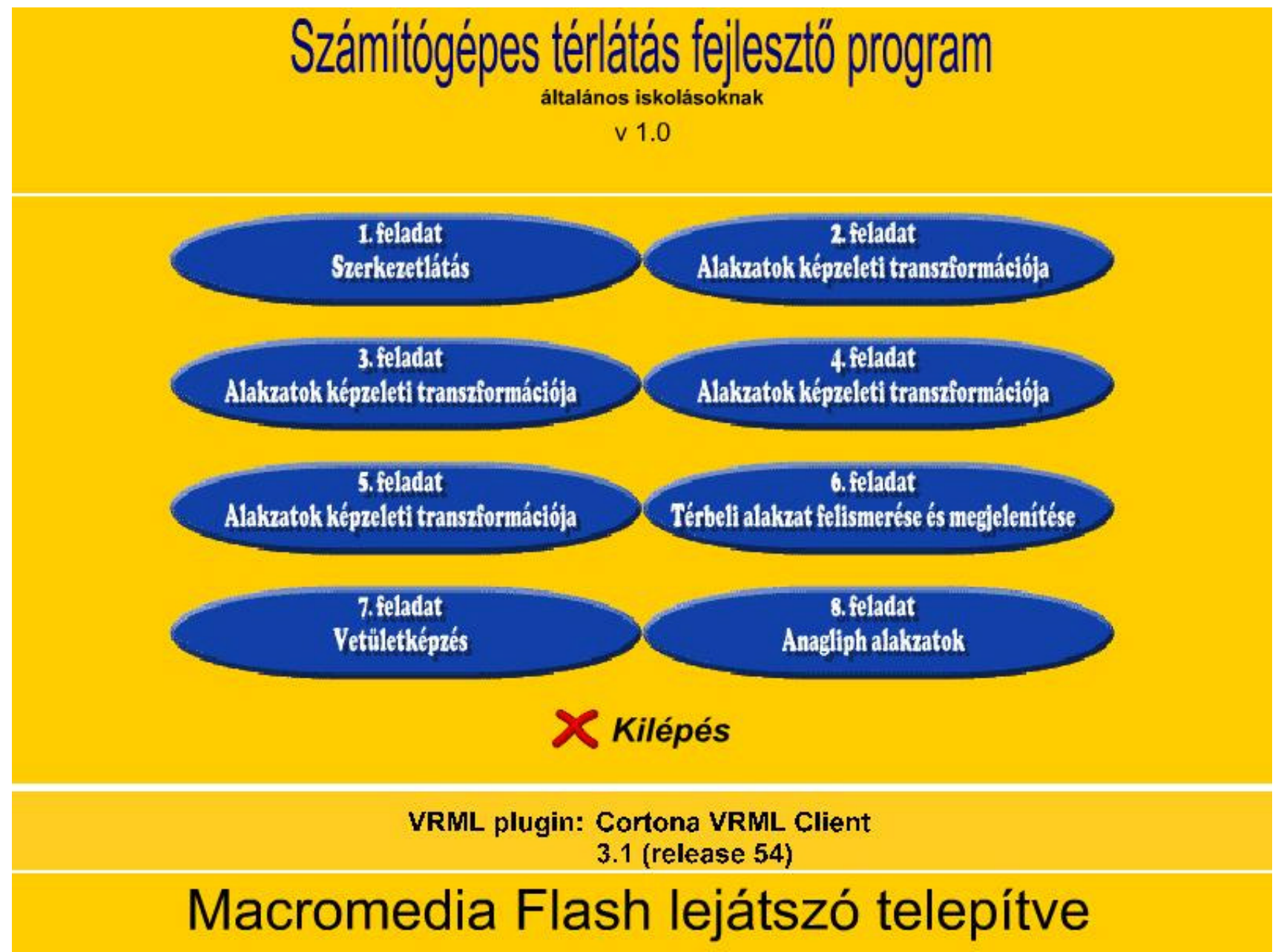

Figure 6: Main menu of the program for the children in the sixths and eighth grade.

Figure 6 depicts the main menu of the program developed for the students in the sixth and eighth grade (Group B and C of the next Section: The course of the investigation). Here the heading of the screen image says "Computer program for developing the space vision, for children in ground education courses". Below this one finds the description of the eight task groups:

- Task 1: Seeing structures

- Task 2: Virtual transformation of forms

- Task 3: Virtual transformation of forms

- Task 4: Virtual transformation of forms

- Task 5: Virtual transformation of forms

- Task 6: Recognition of forms in space and their display

- Task 7: Producing projections

- Task 8: Anaglyph forms

Below this there is a radio-knob for Exit, and two rows informing on the availability of a VRML plug-in and of the Macromedia Flash player. 


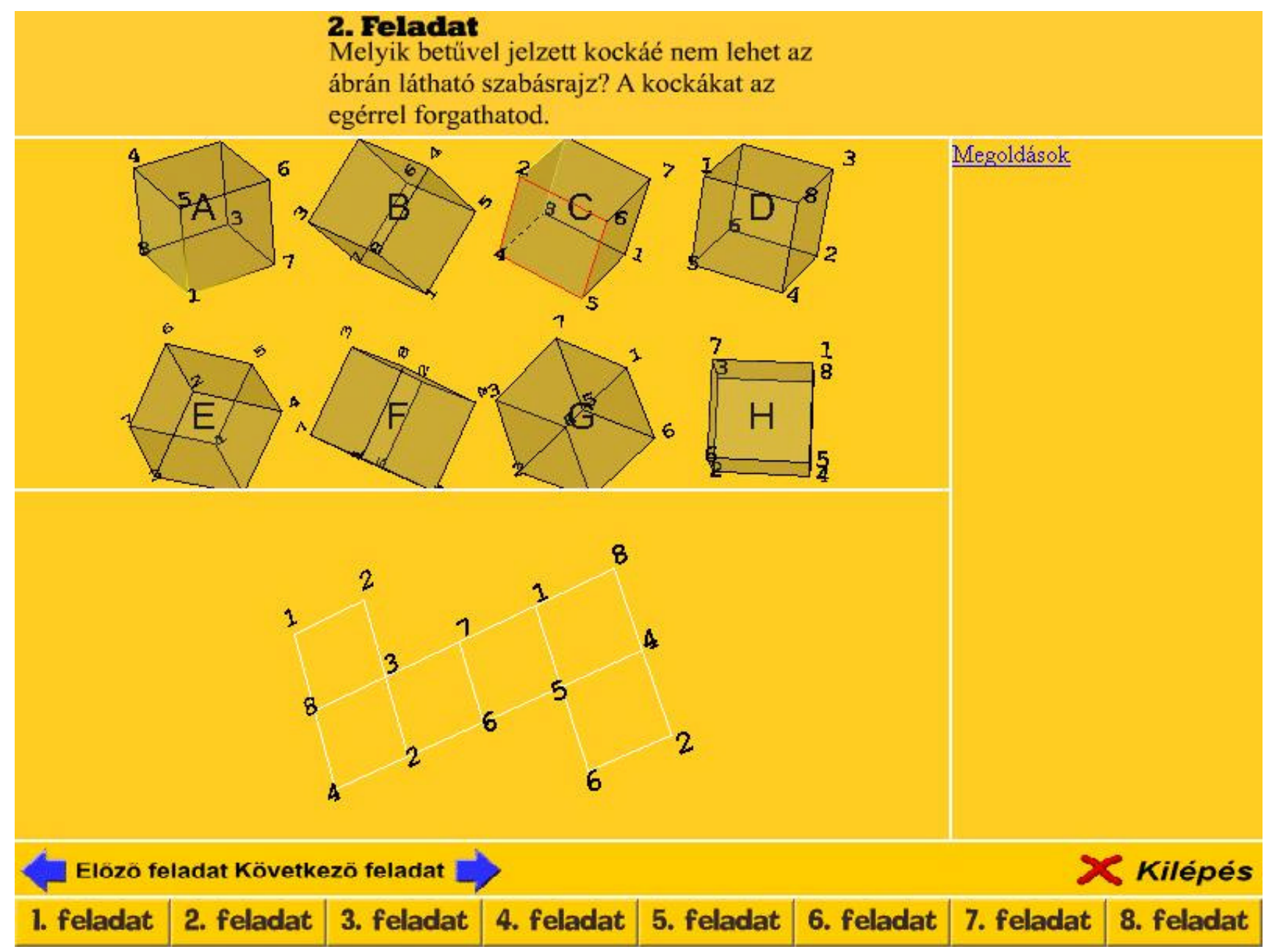

Figure 7: Task 2 of the program tested with the children in the sixths and eights grade. At the top of the screen you can read: "Task 2: Which of the cubes can not be produced by folding the mashdiagram seen in the lower part of the screen. You can turn the cubes with the mouse." At the bottom of the screen there are knobs for going to the previous or next task, or selecting one of the eight tasks, and to exit the program. The results have to be written into the square shown on the right hand side of the screen.

Figure 7 shows an example task from this program. Here the children had to find which of the eight cubes shown in the upper half of the screen could be assembled by folding the mesh diagram shown in the lower part of the screen. They could turn the cubes by the help of the mouse for looking at the cubes from different directions. Their guess had to be written in the square on the right hand side of the screen. For self-test they could also get the program to enumerate the correct answers. At the bottom of the screen there are navigation knobs to move to another task, or to exit the program.

Two further tasks are shown in Figure 8. In the task shown on the left hand side the student had to find out which of the bodies depicted in blue could be put through the hole of the body depicted in red. Both the blue and the red body could be turned with the mouse. In the task shown on the right hand side, the student had to find out which of the basic forms shown in the lower part of the screen had to be used to build the bodies shown in the upper part of the screen. For some of these bodies two, for some three basic forms have to be used. The mouse could turn the bodies, and by clicking on the body the correct answer could be obtained. 

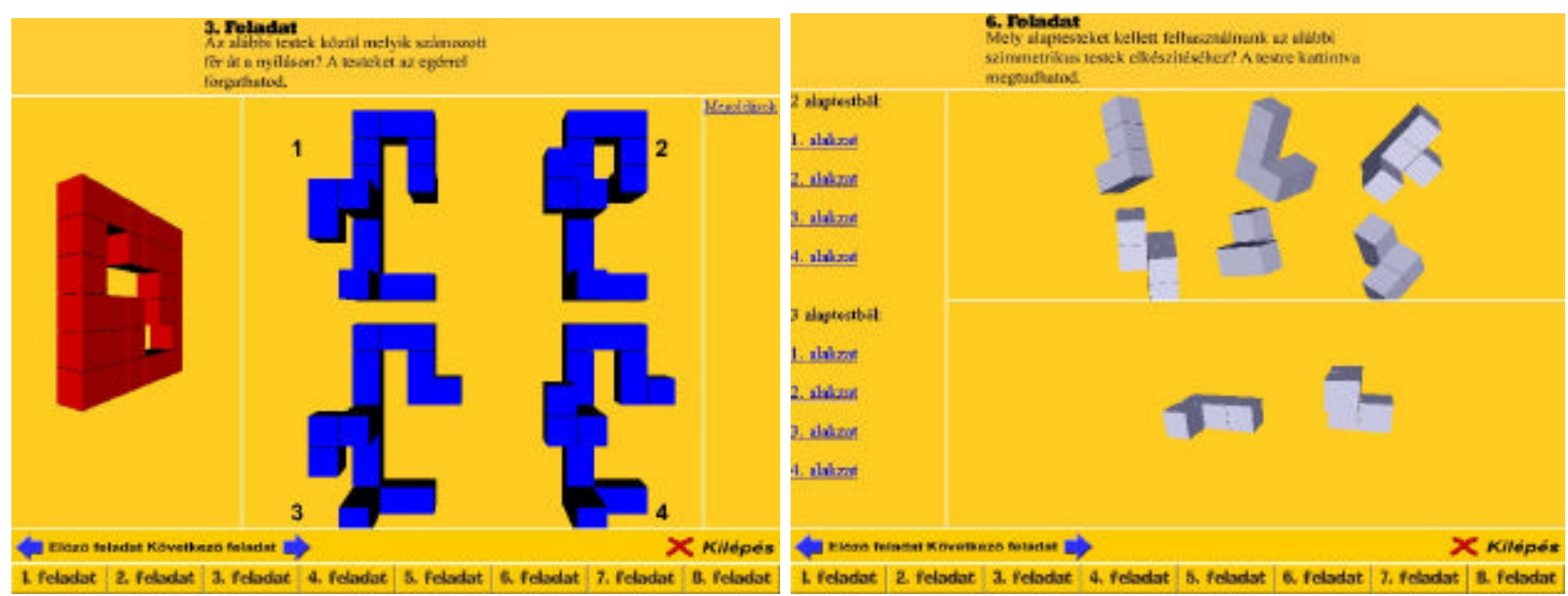

Figure 8: Two tasks from the group prepared for the children in the sixth and eight grade (Group B and C) (for details see text).

The hardware requirements to be able to run these programs are:

- Pentium processor.

- SVGA monitor with a resolution of $800 \times 600$.

- Windows operating system with built in Internet browser (Internet Explorer).

- Mouse.

- CosmoPlayer.

\section{The Course of the Investigation}

We have conducted several tests using our pilot and final programs. In the first test 18 15-year-old high school students participated (Group A, see Table 1). In this test we wanted to clarify whether there is any difference if the students practice with a multimedia or a virtual reality program. First they performed a paper test, and then an ophthalmologic test was done. Half of the class used the multimedia program, the other half the virtual reality program. Then the paper test was repeated. We have investigated whether the multimedia or the virtual reality task helped more to get better scores in the second paper test, i.e. which method increased their space vision more. In our experiments we compare the above tests with the results of the ophthalmologic investigations and the school marks of the students in mathematics as well. Some studies show that space tests are useful to predict the achievements of students in subjects as geometry, mathematics and chemical studies (Ghiselli, 1973).

\begin{tabular}{|c|c|c|c|c|}
\hline Group & Age group & Number of students & girls & boys \\
\hline A & High school, 15 years old & 18 & $9(50 \%)$ & $9(50 \%)$ \\
\hline B & Sixth grade, 12 years old & 17 & $10(59 \%)$ & $7(41 \%)$ \\
\hline C & Eighth grade, 14 years old & 25 & $11(44 \%)$ & $14(56 \%)$ \\
\hline
\end{tabular}

\section{Table 1: Age and gender of students participating in the tests.}

Based on the results of the first test a second program was prepared. This was tested in two schools, in two classes (sixth grade, 12 year-old students: Group B and eighth grade, 14 year-old students: Group C, see Table 1). The class in eighth grade consisted of students with generally better scores than those in the sixth grade. Thus the total number of students who participated in the tests was 60 . This is a relatively small number, but it permitted us to draw some conclusions on the effectiveness of the programs. 


\section{Evaluation}

\section{Results at the High School}

The two paper tests conducted before and after the training with the multimedia and virtual reality computer tests has been evaluated and compared. In the first test students had to solve 20 tests, and we evaluated their results by computing the number of good answers related both to the total number of tests and to the number of tests the students dealt with (due to the high number of tests and the relatively short time to perform the task, most students did not solve all the tests). In the final evaluation we used only the ratio: good answers/solved tests.

In the second paper test we have selected only seven test sheets, and evaluated these similarly to that of the first test. Figure 9 shows the paper test results of the high school students before and after practicing with the computer tests.

The average of the results for girls: first test: $61 \%$, second test $70 \%$; boys: first test: $74 \%$, second test: $82 \%$. Comparing the two groups (those who practiced using our programs and those who did not use it) shows the following result: Those who could use the computer programs got $32 \%$ better scores on the second test; those who could use only the paper test got only $1 \%$ better scores.

It is interesting to mention that for one student the ophthalmologic test showed absolutely no space vision, (on the right hand side in the third row from the top) despite of this his second test, after practicing with the computer tests, got slightly better.
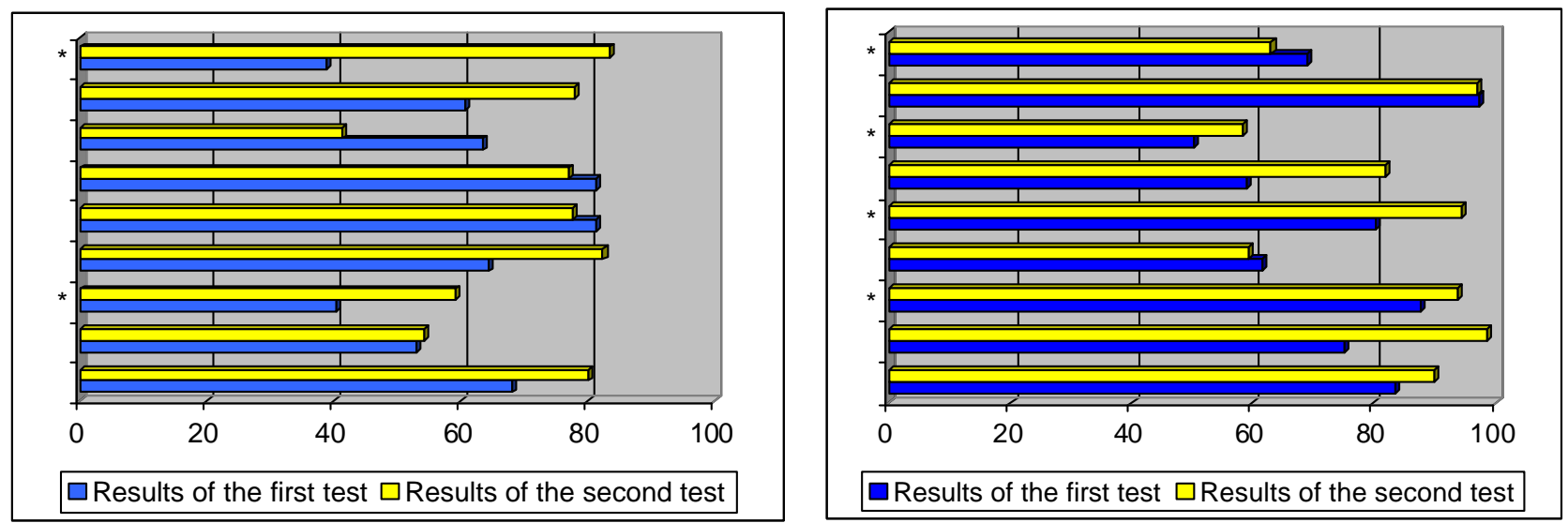

Figure 9: Test results of the high school (Group A, 15 years old) students: On the left hand side results of the girls, on the right hand side those of the boys can be seen. Test results of the first test are depicted in blue, of the second test in yellow. The students marked with a $*$ practised using the computerized tests.

\section{Results in the Elementary Education Classes (Sixth and Eighth Grade, Group B and C)}

Earlier investigations (Horváth, Kiss \& Horváth, 1991) have shown that the following significantly influences the state of the development of space vision:

- The gender of the person,

- His or her mark in mathematics,

- His or her mark in drawing. 
Sik-Lányi, Lányi \& Tilinger

\begin{tabular}{|c|c|c|c|c|c|c|c|c|c|}
\hline (12 years old) & \multicolumn{3}{|c|}{ girls } & \multicolumn{3}{|c|}{ boys } & \multicolumn{3}{|c|}{ total } \\
\hline Group B & Test 1t & Test 2 & change $\%$ & Test 1t & Test 2 & change $\%$ & Test 1t & Test 2 & change $\%$ \\
\hline 1. task group & 100 & 94 & -6 & 100 & 94,3 & $-5,7$ & 100 & 94,1 & $-5,9$ \\
\hline 2. task group & 37,3 & 37,9 & 0,6 & 42,8 & 47,3 & 4,5 & 39,6 & 41,8 & 2,2 \\
\hline 3. task group & 58,9 & 59,0 & 0,1 & 60 & 48,7 & $-11,3$ & 59,4 & 54,8 & $-4,6$ \\
\hline 4. task group & 78,1 & 80,9 & 2,8 & 97,6 & 100 & 2,4 & 86,1 & 88,8 & 2,7 \\
\hline Total. & 56,6 & $\mathbf{5 8 , 7}$ & 2,1 & 62,4 & 61,5 & $-0,9$ & 59 & 59,9 & $\mathbf{0 , 9}$ \\
\hline (14 years old) & \multicolumn{3}{|c|}{ girls } & \multicolumn{3}{|c|}{ boys } & \multicolumn{3}{|c|}{ total } \\
\hline Group C & Test 1t & Test 2 & change $\%$ & Test 1t & Test 2 & change $\%$ & Test 1t & Test 2 & change $\%$ \\
\hline 1. task group & 100 & 100 & 0 & 97,4 & 100 & 2,6 & 98,6 & 100 & 1,4 \\
\hline 2. task group & 46,7 & 61,8 & 15,1 & 62,3 & 61,8 & $-0,5$ & 55,1 & 61,8 & 6,6 \\
\hline 3. task group & 60,9 & 82,4 & 21,6 & 84,9 & 94,4 & 9,5 & 73,9 & 88,9 & 15 \\
\hline 4. task group & 83,1 & 84,7 & 1,6 & 96,2 & 97,4 & 1,2 & 90,2 & 91,6 & 1,4 \\
\hline Total. & 61,9 & 77,2 & 15,3 & 78,4 & 84,5 & 6,1 & $\mathbf{7 0 , 8}$ & 81,1 & 10,3 \\
\hline
\end{tabular}

Table 2: Results according to the task-groups and gender.

We have investigated also these factors in the elementary school groups. Further on we also tried to compare the scores of the two groups (sixth and eighth grade). In both classes the students had to fill in the paper test, then in a second class they could practice with the computer tests, and in a third class they filled in the paper test once again (this third class took place one week after the first one). The Tables 2 , 3 and 4 show the results of the evaluations.

\begin{tabular}{|c|c|c|c|c|c|c|c|c|c|c|c|c|}
\hline $\begin{array}{c}\text { Results in } \\
\text { mathematics }\end{array}$ & \multicolumn{3}{|c|}{2} & \multicolumn{3}{|c|}{3} & \multicolumn{3}{|c|}{4} & \multicolumn{3}{|c|}{5} \\
\hline $\begin{array}{c}\text { Group B } \\
\text { (12 years old) }\end{array}$ & $\begin{array}{c}\text { Test } \\
\text { 1t }\end{array}$ & Test 2 & $\begin{array}{c}\text { change } \\
\%\end{array}$ & $\begin{array}{c}\text { Test } \\
\text { 1t }\end{array}$ & Test 2 & $\begin{array}{c}\text { change } \\
\%\end{array}$ & $\begin{array}{c}\text { Test } \\
\text { 1t }\end{array}$ & Test 2 & $\underset{\%}{\text { change }}$ & $\begin{array}{c}\text { Test } \\
1 \mathrm{t}\end{array}$ & Test 2 & $\underset{\%}{\text { change }}$ \\
\hline 1. task group & 100 & 100 & 0 & 100 & 100 & 0 & 100 & 97,5 & $-2,5$ & 100 & 91 & -9 \\
\hline 2. task group & 18,3 & 14,9 & $-3,4$ & 60 & 41,7 & $-18,3$ & 40 & 47 & 7 & 41,6 & 41,3 & $-0,4$ \\
\hline 3. task group & 58 & 40,1 & $-17,9$ & 58,3 & 41,7 & $-16,6$ & 59,2 & 45,7 & $-13,5$ & 59,8 & 62,7 & 2,8 \\
\hline 4. task group & 100 & 100 & 0 & 100 & 100 & 0 & 95,8 & 94,3 & $-1,4$ & 78,1 & 83,2 & 5,1 \\
\hline Total. & 52 & 47,7 & $-4,3$ & 69,4 & 57,2 & $-12,2$ & 60,7 & 59,3 & $-1,4$ & 58,6 & 61,5 & 2,9 \\
\hline $\begin{array}{c}\text { Results in } \\
\text { mathematics }\end{array}$ & \multicolumn{3}{|c|}{2} & \multicolumn{3}{|c|}{3} & \multicolumn{3}{|c|}{4} & \multicolumn{3}{|c|}{5} \\
\hline $\begin{array}{c}\text { Group C } \\
\text { (14 years old) }\end{array}$ & $\begin{array}{c}\text { Test } \\
1 \mathrm{t}\end{array}$ & Test 2 & $\underset{\%}{\text { change }}$ & $\begin{array}{c}\text { Test } \\
\text { 1t }\end{array}$ & Test 2 & $\underset{\%}{\operatorname{change}}$ & $\begin{array}{c}\text { Test } \\
1 \mathrm{t}\end{array}$ & Test 2 & $\underset{\%}{\text { change }}$ & $\begin{array}{c}\text { Test } \\
\text { 1t }\end{array}$ & Test 2 & $\underset{\%}{\text { change }}$ \\
\hline 1. task group & 100 & 100 & 0 & 100 & 100 & 0 & 100 & 100 & 0 & 96,2 & 100 & 3,8 \\
\hline 2. task group & 60 & 19,8 & $-40,2$ & 46,6 & 51,7 & 5 & 58,7 & 80 & 21,3 & 54,4 & 72,9 & 18,5 \\
\hline 3. task group & 83,2 & 100 & 16,8 & 55,1 & 66,5 & 11,4 & 77,9 & 95,5 & 17,6 & 79,5 & 90,3 & 10,8 \\
\hline 4. task group & 100 & 100 & 0 & 87,4 & 94,3 & 7 & 94,9 & 94,3 & $-0,6$ & 90,7 & 86,4 & $-4,3$ \\
\hline Total. & 77,8 & 73,3 & $-4,5$ & 60,7 & 69,4 & 8,6 & 74,5 & 90,4 & 15,9 & 72,3 & 84,4 & 12,1 \\
\hline
\end{tabular}

Table 3: Results according to the task-groups and marks in mathematics. 
Using Virtual Reality to Improve Space and Depth Perception

\begin{tabular}{|c|c|c|c|c|c|c|c|c|c|}
\hline $\begin{array}{l}\text { Results in } \\
\text { drawing }\end{array}$ & & 3 & & & 4 & & & 5 & \\
\hline $\begin{array}{l}\text { Group B } \\
\text { (12 years old) }\end{array}$ & Test 1t & Test 2 & change $\%$ & Test 1t & Test 2 & change $\%$ & Test 1t & Test 2 & $\begin{array}{c}\text { change } \\
\%\end{array}$ \\
\hline 1. task group & 100 & 90 & -10 & 100 & 100 & 0 & 100 & 91,8 & $-8,2$ \\
\hline 2. task group & 60 & 36,60 & $-23,4$ & 32 & 36,6 & 4,6 & 41,2 & 44,6 & 3,4 \\
\hline 3. task group & 50 & 33,3 & $-16,7$ & 68,1 & 47,6 & $-20,5$ & 56,3 & 60 & 3,7 \\
\hline 4. task group & 100 & 100 & 0 & 96,6 & 100 & 3,4 & 80,1 & 82,7 & 2,6 \\
\hline Total. & 66,7 & 51,5 & $-15,2$ & 60,5 & 57,9 & $-2,5$ & 57,6 & 61,5 & 3,9 \\
\hline \begin{tabular}{|l} 
Group C \\
(14 years old)
\end{tabular} & Test 1t & Test 2 & change \% & Test 1t & Test 2 & change \% & Test 1t & Test 2 & $\underset{\%}{\text { change }}$ \\
\hline 1. task group & 100 & 100 & 0 & 100 & 100 & 0 & 96,9 & 100 & 3,1 \\
\hline 2. task group & 60 & 80 & 20 & 56,1 & 65,3 & 9,2 & 53,6 & 77,5 & 23,9 \\
\hline 3. task group & 100 & 94,4 & $-5,7$ & 64,5 & 83,2 & 18,7 & 84 & 94,6 & 10,7 \\
\hline 4. task group & 100 & 66 & -34 & 91,5 & 96,2 & 4,7 & 92,4 & 88,8 & $-3,5$ \\
\hline Total. & 83,3 & 84,3 & 0,9 & 68,5 & 81 & 12,5 & 73,8 & 81,5 & 7,7 \\
\hline
\end{tabular}

Table 4: Results according to the task-groups and marks in drawing.

One can see a major difference between the sixth and eighth grade results. In both groups better marks have been achieved after practicing, but this was very small in Group B (sixth grade), only about $1 \%$. In Group $\mathrm{C}$ the difference was larger, about $10 \%$.

For both Group B and C the difference in gender could be observed also in our test: the boys scored better in both groups and tests. The increase between the two tests (before and after practicing) was, however, larger for the girls than for the boys.

Evaluating the interrelationship with the marks in mathematics we found the following:

For both Group B and C: After the first test there was no significant correlation between the students with better and inferior marks. The increase in scores was, however, larger for the students with better marks.

The interrelationship between test results and marks in drawing is not significant. This is due to the fact that most students had relatively good marks from drawing (only one student had the lowest mark, and he had an excellent space perception).

\section{Summary}

The space-vision can be augmented in childhood. In our experiments virtual reality applications were used to test 15-year-old high school students and 12 - 14 year-old elementary school children. The high school students first solved traditional paper tests then they were screened by orthoptical tests (visual acuity, ophthalmic investigations, space- and depth-vision tests).

Two computer tests have been prepared: one for high school students, the other for elementary school students. Both tests were made using VRML virtual reality program and the main menu by HTML application. The students could practice using these tests, and after such practice sessions the paper tests were re-run. Our investigations have shown that the computer programs can help children gain better space perception. Thus it can be recommended that such programs should be included in the curriculum of 12 to 15 year-old children. 


\section{References}

Ghiselli, E. E. (1973). The validity of aptitude tests in personnel selection. Personal Psychology, 26, 461-477.

Johnson, A., Moher, T., Ohlsson, S., \& Leigh, J. (2001). Exploring multiple representation in elementary school science education. Proceedings of the Virtual Reality 2001 Conference, Yokohama: IEEE Computer Society, 201-208.

Hodges, L. (2001). Using the virtual world to improve quality of life in the real world. Proceedings of the Virtual Reality 2001 Conference, Yokohama: IEEE Computer Society, 1-3.

Horváth, J., Kiss, A. \& Horváth, L. (1991). Néhány gondolat a térszemlélet fejlesztésérol. BDTF Tudományos Közleményei 8, Módszertani dolgozatok, Szombathely.

Séra, L., Kárpáti, A., \& Gulyás, J. (2002). A térszemlélet fejlodése és iskolai fejlesztése. Comenius Kiadó, Pécs, 2002

Lányi, C. (2002). http://vision.vein.hu/mmvv/

\section{Biographies}

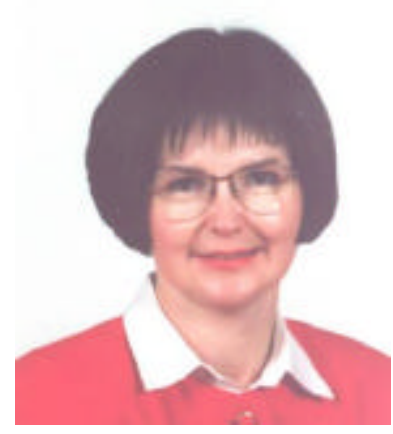

Dr. Cecília Sik-Lányi is associate professor at the University of Veszprém, Department of Image Processing and Neurocomputing. She studied Mathematics and Computer Science (M.S.) - József Attila University, Szeged, and teacher of mathematics (Berzsenyi Dániel Teacher Training College). She obtained the degree of Dr. Univ. at the University of Veszprém, Veszprém, Hungary in Physical-chemistry, and of PhD at the University of Veszprém, Hungary in Computer Science. She reads and leads laboratory studies on Multimedia and Virtual Reality. Her research area is in Multimedia and Virtual Reality in education and rehabilitation.

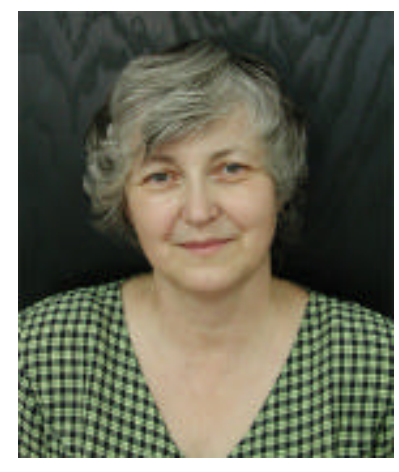

Dr. Zsuzsanna Lányi is Head of the Ophthalmologic Department of the Ferenc Csolnoky Hospital and works also at the county clinic of Veszprém. She has both a diploma for general medicine and ophthalmology. She deals with children's ophthalmology since 1988, and specialized in this subject.

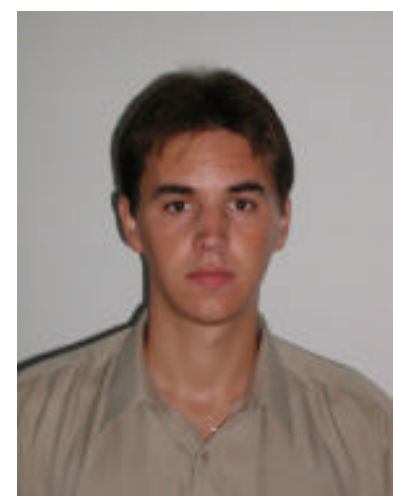

Ádám Tilinger is a graduate student of the University of Veszprém. His paper at the National Youth Scientific Club competition earned a third price. His master's degree dissertation dealt with the production and use in rehabilitation. 